\title{
Using Portable Computer Technologies to Support Learning Environments
}

\author{
Paul Newhouse \\ School of Education, Edith Cowan University Mount Lawley, Western Australia, \\ p.newhouse@cowan.edu.au
}

\begin{abstract}
This paper addresses questions concerning the use of portable computer devices in schools by proposing a framework within which to address the questions, presenting an example, and synthesising the findings of research. The benefits and barriers to implementing portable technologies are discussed leading to some recommendations.
\end{abstract}

\section{INTRODUCTION}

Since the first computers became available to educators many have provided rationales for their use to support learning. As the technology has become more powerful, at lower cost, these arguments have become more insistent and linked to discussions of 'reforming' schooling (e.g. Clouse \& Nelson, 2000). This paper does not debate whether computers should be used but, rather, considers the use of portable computing systems.

Understandings of the link between schools, learning and computers are critical to a discussion of the use of computers in schools. This paper will assume that educators should adopt technologies that address educational problems and/or improve productivity. The rationale for the use of a technology to support learning should arise from a sense of dissatisfaction with the educational opportunities offered to learners and a striving to do better (Schank \& Cleary, 1995).

There is gathering momentum for the use of computers to support learning environments in schools that better reflect constructivist principles (e.g. Clouse \& Nelson, 2000). There is a convergence of support for constructivism, clearly explained in the report by the Committee on

The original version of this chapter was revised: The copyright line was incorrect. This has been corrected. The Erratum to this chapter is available at DOI: 10.1007/978-0-387-35701-0_35 
Developments in the Science of Learning (2000). A critical component is the concept of proximal learning with computer technologies adding to the range of resources that may be used to provide support for student learning (DeCorte, 1990). Technology may support those learning environments that are known to be ideal but have not been implemented widely. The Committee (2000) addressed the issue of what should be considered in developing learning environments and defined "four interrelated attributes of learning environments that need cultivation" (p. 23): learner-centred; knowledge-centred; assessment-centred; and community-centred. They suggested that these provided challenges for education systems, some of which may be met with ICT solutions. Five ways to use ICT to establish and sustain effective learning environments were suggested. These, along with similar theses, provide frameworks to guide the implementation of computer support for constructivist learning environments.

\section{A SECONDARY SCHOOL EXAMPLE}

For three months in 2002 the author conducted research in a Society and Environment class for 13 year olds, where a class-set of Toshiba notebook computers with wireless networking was available for use during class time. The author worked with the teachers to implement a new problem-focussed, project-based programme. The programme was based upon the idea that the students would work in groups of four on a project that would aim to solve a problem and be open ended, practical, collaborative and involve the creation of new knowledge. The student groups were to produce a number of assessable items including maps and a physical model, to present in a multimedia presentation. The only task that had to involve the use of the computers was a Powerpoint slideshow although they were encouraged to use the computers for any of the other tasks and to support group processes. The project aimed to develop and use mapping skills and knowledge and culminate in a multimedia presentation. It was described in a document provided to the students as,

The School is developing a Strategic Plan for the year 2050. The school needs to be able to predict what it needs to offer its clients now so that they can put plans in place. The School favours developing another campus in the Perth Hills as well as maintaining the current campus. The School are asking for tenders to redevelop the school.

Initial background data indicated that almost all of the 24 students were well positioned to benefit from computer-supported learning experiences at school and at home. They appeared to have the necessary skills and positive 
attitudes. However, there was a need to address some gaps in their knowledge and skills and the teacher-dependency of many students.

The physical configuration of the classroom was modified a number of times to accommodate whole-class, group-work and individual access to the computers. Computers were usually used at the desks although often if the batteries were flat the computers were used at the long benches at the side of the classroom so that power points could be used. In the 21 lessons that were observed the computers were used for about $50 \%$ of the available class time, which is quite a high use of a resource. The short lesson time (mainly 45 minutes) contributed to a relatively large proportion of time spent in transition (15\%). Overall the students spent about half the time working individually or in groups, an indication that the environment was not teacher-centred. On a field trip to a national park in the hills overlooking Perth eight students ( 2 groups) collected a variety of pre-determined data on one of three sites that had been marked out with help from a handheld GPS system.

Almost all students indicated that they enjoyed the project and perceived the computers as being most useful for creating slideshow presentations, drawing logos and to a lesser extent collecting information and instructions from the intranet. Many did not consider the computers useful for drawing the maps. In the interviews it became clear that one important reason was that they wanted to use a mouse rather than the AccuPoint Device. However, generally problems in using the computers were minimal.

A number of recommendations were made to the teacher and school administration to improve the implementation of the project, most being procedural. In terms of the use of the computers, the students needed an easy method of file transfer between school and home, and needed to be encouraged to use the intranet information and CorelDraw for the map drawing. Having their own portable devices with some locally stored information would have addressed a number of the concerns.

Was the teacher in the research project able to use the notebook computers to support a more constructivist based learning environment, and did the portability of the technology help? An analysis was conducted of the changes instigated by the teacher, and the outcomes of these changes, by mapping them against the four learning environment attributes provided by the Committee on Developments in the Science of Learning (2000). This showed a move to a more constructivist environment. An analysis of the ways in which ICT was used to support the learning environment was also conducted.

Why did the teacher choose particular applications of ICT and would other teachers choose similar applications? Why don't more teachers 
implement such programmes and why was this teacher doing so only in 2002 ?

\section{TEACHER CHOICE OF COMPUTER SUPPORT}

Since the early 1990s the author has conducted research into the impact of computer use on learning environments in schools and the factors influencing implementation of computer support for learning. As a result a model has evolved to explain the relationships involved (Newhouse, 1998). (A schematic representation of the link between the main constructs can be viewed at http://edresearch.ed.ac.cowan.edu.au/paul/model.htm.)

The model starts with a consideration of the learning environment and the actions of the teacher within the environment since almost always the teacher determines whether computers will be used in a learning activity, even where the students have their own computers (Newhouse, 1998). The extent to which teachers facilitate computer support for learning is determined by a balance of psychological forces (indicating a resultant action) tempered by the presence of obstacles associated with the learning environment.

Of the forces experienced by teachers, there are some that encourage and others that discourage them from facilitation of computer use with the resultant force determining the extent (both quantitatively and qualitatively). This extent, or Level of Facilitation (LoF) is represented by an 'energy level' plateau with an initial 'hump' (developed from Vernooy-Gerritsen's (1994) model) representing the need to overcome obstacles. These forces are primarily perceptions in the mind of the teacher that ultimately influence actions, and may be based on external entities, or internal beliefs, or a combination.

Obstacles are external to the teacher being those things that could be removed immediately by the actions of another person or the teacher. Both negative forces and obstacles represent barriers to increased facilitation of computer support. The difference is that to change a force requires a change in the teacher, while removing an obstacle does not. However, the nature of obstacles and their removal are directly related to the teacher so that an obstacle may be diminished by long-term changes in the teacher but may also be counteracted immediately by the actions of other people.

The affect of the resultant force on the LoF of computer support for learning is mediated through the teacher's Type of Response (ToR) to the opportunities. However, the LoF is also dependent on the affect of obstacles associated with the learning environment. Because the technology is an interactive element of the environment the LoF has an impact on the learning 
environment completing a feedback loop. This explains why successful facilitation leads to increasing levels of facilitation. This model may be applied to choosing a portable computing solution.

\section{CHOOSING A PORTABLE COMPUTING SOLUTION}

The ideal solution for many educators (e.g. Hill, Reeves \& Heidemeier, 2000; Rowe, 1993) is for ubiquitous access to an adequate level of computer processing and software relevant to student learning needs. The question is whether this is best provided through the use of portable computer systems, reliance on network access, or a combination as described by Collis (1989). Currently in most Australian schools ubiquitous access means either the use of a computer laboratory or portable devices (the sharing of classroom-based work-stations may allow pseudo-ubiquitous access). Many (e.g. Rowe, 1993) argue against the computer laboratory scenario because it tends to promote techno-centricity. Alternatively portable computer systems may be used wherever the students are, supporting individual or group work in what could be termed computer-saturated environments.

There are many ways in which it could be considered that portable computing supports ubiquitous access, from portable hardware to portable software and data. Students need access to their data files with appropriate software and hardware. One solution (e.g. notebook) is to carry some of the hardware (including a processor), software and data files. Another is to carry data files on a disk and access software and hardware in each place students are required to work. Alternatively, students could access their files and software configurations on a server with access through networked devices. Where portable computer devices are used there is further choice in terms of functionality and size from the traditional notebooks, to handheld PDAs (Personal Digital Assistants), Palmtops, and Tablet PCs.

\subsection{Portability removes obstacles and generates positive forces}

For all Australian schools it is no longer ridiculous to suggest that every student have a portable computer device. Becker (2001) has shown that the cost is comparable with implementing desktop solutions. The question is whether the portability of the systems provides benefits beyond that of alternative solutions such as thin or thick client systems? 
There are a number of key benefits of portable computing for schools that researchers (e.g. Gardner, Morrison, Jarman, Reilly \& McNally, 1994b; Hill et al., 2000; Rowe, 1993) tend to quote, including: ubiquitous and flexible access, a greater level of invisibility, reduction of techno-centric focus, and better support for constructivist environments leading to better support for student learning. Where the computers are student-owned further benefits are perceived, such as: customization of computer systems, increased student responsibility for the management of data, and assumption of student access to the computer at home.

Increasingly research findings are supporting, with some exceptions, these perceived benefits. Most studies have found that students like using portable computers (Walker, Rockman \& Chessler, 2000) with Gardner et al. (1994b) going further to conclude that because students are less likely to perceive that they were going to computing this more readily permits the integration of computer use with any learning task. However, students respond to and use computers in different ways (Rowe, 1993).

Some research has found positive, although inconsistent, effects on student achievement (Walker et al., 2000). A large early study found little improvement in cognitive outcomes that it was argued was because the computers were used to support process-oriented attainment targets rather than the measured content-oriented targets (Gardner, Morrison, Jarman, Reilly \& McNally, 1994a). A number of studies (e.g. Crawford \& Vahey, 2002, p. 40; Newhouse, 1998; Walker et al., 2000) have found that the increased ubiquity and flexibility has led to more use and a greater range of use of the technology.

There is tremendous variation in teachers' responses to the availability of portable computing. Some teachers find the availability liberating and supportive in the way Sandholtz, Ringstaff and Dwyer (1992) describe, "in the beginning of the project teachers sometimes thought only of how the technology increased their workload, before long many teachers doubted they could ever return to a traditional classroom" (p. 480). Gardner et al. (1994b) reported that some teachers interacted more with students and felt that "the portables had provided them with opportunities for innovative teaching approaches" (p. 31).

A number of studies have found that by teachers facilitating the use of portable computing devices they are encouraged to use more constructivist pedagogical practices probably because of the focus on student action resulting from control of the computers (Loader, 1993; Metis Associates, 1999; Walker et al., 2000). In terms of the model the availability of portable computers may provide some powerful forces (e.g. availability and flexibility) to encourage teachers to facilitate the use of computers with students, while overcoming some obstacles (e.g. adequate access). Even so 
there will still be some opposing forces and additional obstacles to overcome.

\subsection{Addressing barriers to portability}

Apart from the cost of the hardware, researchers have identified some barriers (either obstacles or opposing forces) to realising the potential of portable computing. There are technical barriers concerning weight, battery life, durability and networking and non-technical barriers concerning teacher skills and experience, school organization, curriculum and pedagogy, and the perceptions, attitudes and beliefs of teachers. Most of the latter barriers do not relate specifically to the use of portable computers.

There are now solutions to most, if not all, of the early technical barriers although one recent study reported some of these as critical obstacles (Hill, Reeves, Grant \& Wang, 2001). In particular, battery life is longer, notebooks are lighter and more durable, and the advantages of IEEE 802.11 radio wireless networking are clear when students take only minutes to open a computer and connect to the Internet (Newhouse, 2001). More recently, a variety of alternative devices, such as PDAs and Tablets, overcome these barriers. Despite this there will still be barriers in some school settings due to using new technologies in physical environments designed for older technologies (Hill et al., 2001).

Apart from the early concerns with the weight of laptops there are broader ergonomic concerns specific to portable computers such as the awkwardness of carrying the computers, some I/O devices (e.g. AccuPoint), and the tendency for use in a variety of environments leading to poor body posture. Harris and Straker (2000) raised this latter concern but suggested that "many of the consequences of their [laptop] use do have solutions" (p. 346) mainly associated with the management of the students and technology.

Shortcomings in the skills and computer-related knowledge of teachers have been well documented (Sandholtz et al., 1992) although more recent research (e.g. Becker, Ravitz \& Wong, 1999; Newhouse, 1998) has highlighted the critical nature of teacher understanding and experience, rather than operational skills. A lack of teacher operational skill is not as critical where student-owned portable computers are used because the students are competent at operating their computers. However, students become readily dissatisfied with inefficient or inadequate integration of computer use with the curriculum. Unfortunately, most teachers have inadequate experience with using computers to support student learning, irrespective of enthusiasm and computer literacy, and significant teaching 
experience (Becker et al., 1999; Newhouse, 1997). This obstacle can be diminished by providing teachers with both technical and curriculum support.

Serious barriers to facilitation of computer support are connected with educational policies and practices, and the organisation of schools. For example, many secondary schools have short lesson times with segregated specialist teachers providing a disintegrated curriculum not sharing resources and expertise which create unnecessary obstacles (Gardner et al., 1994b; Newhouse, 1998; Sandholtz et al., 1992). These are obstacles that can be addressed with appropriate system and school policy decisions as evident in a number of Australian 'laptop schools' (Loader, 1993).

The link between curriculum, pedagogies and use of computers is encapsulated in the aim to embed computer support as a critical component of the learning environment by integrating with the curriculum and pedagogical practice. Unfortunately computer use has often been an interesting but readily discarded accessory (Becker, 1994). Disappointingly, a recent study reported that even with laptops, the use of the technology support was still "outside the curriculum" (Hill et al., 2001, p. 61) with the only real impact being increased access to online information and an increase in presentations.

Irrespective of the obstacles there are some teachers who facilitate the use of computers more readily than others. Teachers whose practices are more instructivist in nature will be less likely to consider computers as useful cognitive tools for students (Newhouse, 1998). Hannafin and Savenye (1993) suggest that teachers may resist changes in learning theory. The need for changes in an internal force based on beliefs is a long-term process and meanwhile the technology may be discarded once obstacles are encountered.

\subsection{Selecting appropriate systems}

Which type of portable computing devices, from the wide array available, should be chosen to suit the needs of learners? There are four interrelated issues that tend to guide the selection for a school: the degree of standardisation required by the school; the degree of user control encouraged by the teacher; the degree of hardware and software portability practicable within the school; the ownership of the hardware and software.

The first two issues pitch ICT maintenance convenience against the link between learning and the technology. Those responsible for maintenance tend to want standardisation while educators guided by constructivist theories want to maximise learner control, and match the variety of learners and learning tasks. Thus the balance should be towards more user control and connectable systems rather than identical systems. An interesting 
manifestation of this balance has been the debate on the merits of 'thin client' technology based on increasing productivity (Good, 2001). However, productivity gains for standardised centralised systems can't be generalized (Friedlander, 2000). The other issues of degree of portability and ownership tend to be related to the first two in that those who advocate standardised, centrally controlled systems tend to support using non-portable centrally owned systems while those advocating maximising learner control tend to want more portable systems with a level of personal ownership.

There is now a wide array of options for providing computer processing support to students varying in size, capacity, speed, and connectivity. Which components of a system need to be carried and which should be left in the classroom or on the server? For example, as a minimum students could just carry a disk with them to plug into processing devices. Or the disk could include some components of operating and applications software, as is the case with the OQO system (OQO Corporation, 2002). Choices are likely to depend on the age and capabilities of the student with some research finding that class sets of school-owned notebooks being a good model for younger students (Newhouse, 2001), with personal ownership models being more suited to older students (Newhouse, 1998). Perhaps in the early years each student could have access to devices such as Tablet PCs kept at school and graduate to notebooks at about the age of 12 years. For the early teenage years most children could own a notebook or smaller device carried to and from school, perhaps graduating to a PDA. Schools would probably have to provide some extra processing and peripheral devices.

Portable devices are eventually individually owned, as with calculators. Should the computers be owned by the students or by the school? This raises three concerns: cost, security, and identity. Although becoming less of a factor, portable devices cost more than equivalents. As devices become the responsibility of the user there may be less concern for their physical security but the implications for the logical security of a school's network and the potential for system incompatibilities are concerns (Kessell, 2001). Research has not found these to be major problems, with the reduced corporate responsibility for physical security offsetting the increase in cost of school network maintenance (Newhouse, 1998). The important sense of personal identity is more readily sustained with personally owned computers (Rowe, 1993). However, this increases the difficulty in the provision of operational support to students who must be more independent. Monitoring inappropriate behaviour is more difficult but, as Crawford and Vahey (2002) found, personal ownership can lead to useful unplanned learning experiences. 


\section{CONCLUSION}

It is relatively safe to suggest that students in the future will have some form of portable computer device. The impact on schooling is difficult to predict. If children do need better schooling and computer support will assist in providing this, then portable computer technologies implemented with the appropriate support will realise the potential so long envisaged. This may require changes to school organization, curriculum, and pedagogy, and will take considerable effort by teachers and depend on their expertise, experience and beliefs.

\section{REFERENCES}

Becker, H. J. (1994). How exemplary computer-using teachers differ from other teachers: Implications for realizing the potential of computers in schools. Journal of Research on Computing in Education, 26(3), 291-321.

Becker, H. J., Ravitz, J. L., \& Wong, Y. T. (1999). Teacher and Teacher-Directed Student Use of Computers and Software. (Teaching, Learning, and Computing: 1998 National Survey. 3). Irvine, California: Center for Research on Information Technology and Organizations, University of California, Irvine.

Becker, J. P. (2001). The wireless revolution. NEA Today, 19(6), 8-10.

Clouse, R. W. \& Nelson, H. E. (2000). School reform, constructed learning, and educational technology. Journal of Educational Technology Systems, 28(4), 289-303.

Committee on Developments in the Science of Learning (Ed.) (2000). How People Learn: Brain, Mind, Experience, and School. Washington, D.C.: National Academy Press.

Crawford, V. \& Vahey, P. (2002). Palm Education Pioneers Program March 2002 Evaluation Report: SRI International.

DeCorte, E. (1990). Learning with new information technologies in schools: Perspectives from the psychology of learning and instruction. Journal of Computer Assisted Learning, 6, 69-87.

Friedlander, D. (2000). Thin-Client Cost of Ownership: The Numbers Don't Add Up (Idea Byte). Cambridge, MA 02142, USA: Giga Information Group.

Gardner, J., Morrison, H., Jarman, R., Reilly, C., \& McNally, H. (1994a). Learning with portable computers. Computers in Education, 22(1/2), 161-171.

Gardner, J., Morrison, H., Jarman, R., Reilly, C., \& McNally, H. (1994b). Personal Portable Computers and the Curriculum (Practitioner Minipaper 13). Glasgow: Scottish Council for Research in Education.

Good, D. G. (2001). Investing in K-12 Technology Equipment: Strategies for State Policymakers (Reports - Evaluative). Denver, CO: Education Commission of the States.

Hannafin, R. D. \& Savenye, S. (1993). Technology in the classroom: The teacher's new role and resistance to it. Educational Technology, 33(6), 26-31.

Harris, C. \& Straker, L. (2000). Survey of physical ergonomics issues associated with school children's use of laptop computers. International Journal of Industrial Ergonomics, 26, 337 - 347.

Hill, J., Reeves, T. C., Grant, M., \& Wang, S. (2001). The Impact of Portable Technologies on Teaching and Learning: Year Two Report. University of Georgia: Athens Academy. 
Hill, J., Reeves, T. C., \& Heidemeier, H. (2000). Ubiquitous Computing for Teaching, Learning, and Communicating: Trends, Issues \& Recommendations. Athens, Georgia: Department of Instructional Technology, College of Education, The University of Georgia.

Kessell, S. R. (2001). Evaluation of the Personal Laptop Program at Penrhos College [19982000]: Final Report. Perth, Western Australia: Curtin University of Technology.

Loader, D. (1993). Reconstructing an Australian school. The Computing Teacher, 20(7), 12 15.

Metis Associates (1999). Program Evaluation: The New York City Board of Education Community School District Six Laptop Project. New York: Metis Associates.

Newhouse, C. P. (1997). The impact of portable computers on classroom learning environments. Australian Educational Computing, 13(1), 5-11.

Newhouse, C. P. (1998). Teachers' responses and classroom learning environments associated with student access to portable computers. Unpublished $\mathrm{PhD}$, Curtin University of Technology, Perth, Western Australia.

Newhouse, C. P. (2001). Wireless portable technology unlocks the potential for computers to support learning in primary schools. Australian Educational Computing, 16(2), 6-13.

OQO Corporation. (2002). OQO Ultrapersonal [online]. OQO Corporation. Available: http://www.oqo.com/ [2002, 3/7/2002].

Rowe, H. A. H. (1993). Learning with personal computers. Hawthorn: Australian Council for Educational Research.

Sandholtz, J. H., Ringstaff, C., \& Dwyer, D. C. (1992). Teaching in high-tech environments: Classroom management revisited. Journal of Educational Computing Research, 8(4), 479505.

Schank, R. C. \& Cleary, C. (1995). Engines for Education. Hillsdale, NJ: Lawrence Erlbaum Associates.

Vernooy-Gerritsen, M. (1994). Schools with SPIRIT, a new approach to implementation. Brisbane: Australian Computers in Education Conference: APITITE'94.

Walker, L., Rockman, S., \& Chessler, M. (2000). A More Complex Picture: Laptop Use and Impact in the Context of Changing Home and School Access (The third in a series of research studies on Microsoft's Anytime Anywhere Learning Program. 3). San Francisco, CA: Rockman et al. 